\title{
A nova regulação educacional e o trabalho docente na pós-graduação brasileira
}

\author{
Olgaíses Cabral Maués \\ Universidade Federal do Pará \\ William Pessoa da Mota Junior \\ Universidade Federal do Pará
}

\section{Resumo}

0 texto apresenta resultados de uma pesquisa que busca identificar as possíveis relações entre a nova regulação educacional e o trabalho docente na pós-graduação stricto sensu no Brasil. O Sistema CAPES de avaliação é central na pesquisa, buscando-se por meio da análise de documentos dessa agência e de revisão bibliográfica dos trabalhos apresentados nas últimas reuniões nacionais da ANPEd identificar as repercussões que o atual sistema de avaliação da pós-graduação está trazendo para o trabalho dos professores na pós-graduação. A intensificação do trabalho, o adoecimento e a disseminação do produtivismo acadêmico são algumas tendências que se consolidam em termos de mudanças na materialidade e subjetividade do trabalho docente.

Palavras-chave: Regulação Educacional. Trabalho Docente. Avaliação. 


\section{The new educational regulations and faculty work in Brazilian graduate courses}

This study presents the results of a literature and documental review aiming at identifying the possible relationships between the new educational regulations and faculty work in stricto sensu graduate programs in Brazil. This work focuses on CAPES' (Coordination for the Improvement of Higher Level Personnel) evaluation system. Through an analysis of the documents of said research foundation and a literature review of the works presented at the last national meetings of ANPEd (National Association of Graduate Studies and Research in Education), the goal of this study was to identify the repercussions of the evaluation system of graduate courses on the faculty work in graduate programs. The results indicate that increased work, illnesses, and the dissemination of an academic emphasis on production are some of the trends that have consolidated as changes in the materiality and subjectivity of faculty work.

Keywords: Education Regulation. Faculty work. Evaluation.

\section{El nuevo reglamento de educación y la enseñanza en cursos de postgrado}

El documento presenta los resultados de una literatura que busca identificar y documentar los posibles vínculos entre la nueva regulación en los programas de educación y la enseñanza, los estudios de posgrado en Brasil. El sistema de evaluación de CAPES es el foco central de la investigación, buscando a través del análisis de los documentos de las agencias y de revisión de la literatura de los estudios presentados en las recientes reuniones nacionales que se ocupan de la cuestión ANPEd identificar los efectos que el actual sistema de evaluación de posgrado está trayendo a la labor de los docentes en programas de postgrado. Los resultados indican que la intensificación del trabajo, las enfermedades y la propagación de una cultura productivista académica son algunas de las tendencias que han ido consolidando en la actualidad en términos de cambios en la materialidad y subjetividad de la enseñanza en la universidad y su reconfiguración en la universidad.

Palabras clave: Régulation Educacional. Trabajo Docente. Evaluación. 


\section{Introdução}

Os impactos das reformas educacionais que vêm se desenrolando na América Latina há cerca de duas décadas são tão profundos que, segundo Oliveira (2009), levaram à constituição de uma nova regulação educativa, assentada em três pilares: a gestão local, o financiamento per capita e a avaliação sistêmica.

Tais mudanças no âmbito da gestão, do financiamento e da avaliação provocaram modificações também no trabalho docente, tanto na educação básica quanto no ensino superior, seja em suas condições objetivas, seja em suas condições subjetivas de realização.

Obviamente que as transformações mais gerais na sociedade enquadram o cenário histórico em que se passam as citadas mudanças na política educacional e no trabalho de professores e professoras, desde fenômenos como a globalização e o neoliberalismo até as oscilações de governo, passando pela crise do sistema capitalista e pela reestruturação dos processos produtivos.

Buscar os nexos entre a emergência dessa nova regulação educativa no Brasil nas últimas décadas e as mudanças no trabalho docente na pós-graduação stricto sensu é o objetivo deste trabalho, resultante de uma revisão da literatura e de documentos concernentes à temática. Para tanto, analisamos artigos publicados no site da Associação Nacional de Pesquisa e Pós-Graduação em Educação (ANPEd) referentes às últimas nove reuniões anuais (2001-2009) da entidade que tratassem da temática de nosso trabalho, isto é, das políticas de avaliação para a pós-graduação no Brasil e suas repercussões sobre o trabalho docente, especificamente nos Grupos de Trabalho (GT) 05 - Estado e Política Educacional, 09 - Trabalho e Educação e 11 - Política de Educação Superior. Selecionamos o banco de dados da ANPEd pela relevância que esta entidade científica apresenta para a pesquisa educacional e para a pós-graduação em nosso país.

Os artigos publicados na ANPEd no período assinalado que, de alguma forma, tratam das relações entre "Avaliação da Pós-Graduação" e "Trabalho Docente" são: "O Trabalho Docente no contexto das Reformas", apresentado na $28^{a}$ reunião anual da ANPEd, ocorrida em 2005; "0 Trabalho Docente no Ensino Superior sob o contexto das Relações Sociais Capitalistas", da $29 a$ reunião, em 2006; "Reféns da Produtividade sobre Produção do Conhecimento, Saúde dos Pesquisadores e Intensificação do Trabalho na Pós-graduação", apresentada na $30^{a}$ reunião, no ano seguinte; e "A Política de Educação Superior para a Formação e o Trabalho Docente: A Nova Regulação Educacional", do ano de 2008. Não tomamos como objeto de análise os trabalhos que tratam de "Trabalho Docente" ou de "Avaliação da Pós-Graduação" isoladamente, mas dos dois temas articulados. Constatamos um baixo número de produções sobre a questão da avaliação e do trabalho docente na pós-graduação. 
Analisamos o V Plano Nacional de Pós-Graduação (2005-2010) e a Ficha de Avaliação 2008-2010, formulados pela Coordenação de Aperfeiçoamento de Pessoal de Nível Superior (Capes), principal agência responsável pela regulação da Pós-Graduação em nosso país, os quais explicitam a concepção de avaliação da Capes e situam o lugar e a dimensão do trabalho docente como objeto de avaliação e regulação dos programas de pós-graduação.

No que se refere ao conceito de 'Regulação', importante ferramenta analítica de nosso trabalho, baseamo-nos nas formulações e aplicações do conceito em Oliveira (2009), Aglietta (1997), Afonso (2009) e Maués (2008) para a compreensão das funções da avaliação em relação direta com as análises atuais sobre as tendências do Trabalho Docente na Pós-Graduação brasileira (Mancebo, 2008; Sguissardi; Silva Jr, 2009).

\section{A avaliação como regulação educacional}

Oliveira (2009) atribui ao conceito de 'regulação' uma considerável importância para a explicação dos processos econômicos, sociais e políticos, apresentando esses processos como algo mais que meras consequências da crise do capitalismo. 0 papel exercido pelas instituições e atores políticos na mediação das relações entre o modo de produção capitalista e os fenômenos sociais que se pretende estudar é a grande contribuição teórica dos regulacionistas para a pesquisa social.

Esse instrumento analítico ganha precisão conceitual a partir dos estudos da Escola Francesa de Regulação. Aglietta (1997), um dos mais conhecidos representantes dessa escola, se dedica a explicar como um modo de produção cria mecanismos para sua autorreprodução social. Para este autor, a regulação representa "o conjunto de mecanismos e de instituições que permitem à acumulação capitalista funcionar durante os períodos relativamente estáveis" (Aglietta, 1997, p. 82) ${ }^{1}$.

Maués (2008) se apoia em autores mais recentes desta Escola para definir o conceito:

0 conceito de regulação é bem explicitado por Maroy e Dupriez (2000), dentre outros. Assim, para esses autores, no sentido amplo, a regulação é entendida como o processo de produção de regras e de orientação das condutas dos atores. Essa compreensão é de que a regulação representa um conjunto de mecanismos que vai permitir o controle, através do qual um sistema busca manter o equilíbrio, ou orientar as ações dos sujeitos. (Maués, 2008, p. 02).

1. Tradução livre do original: "L'ensemble des mécanismes et des institutions qui permettent à la fonction d'accumulation du capital au cours des périodes relativement stables". 
Maroy (2006) chama a atenção para o fato de que a regulação não produz necessariamente a ordem e o ajuste face aos problemas e disfunções do sistema. Para ele, a chamada multirregulação (institucional e política) pode também gerar a desordem e as contradições. Para este autor, a regulação é polissêmica, reenviando ao mesmo tempo à busca do equilíbrio em um sistema de ação em movimento e às necessárias adaptações de um sistema nas suas relações com o meio ambiente, este, por vezes, origem de perturbações.

No âmbito da educação,

esta discussão aparece como resultado de um novo rearranjo ao nível macro, redefinindo as bases sobre as quais se assenta a regulação social. A tensão presente no contexto da globalização entre as dimensões locais e globais tem forjado uma nova regulação social e educativa. As novas formas de gestão e financiamento da educação constituem medidas políticas e administrativas de regulação dos sistemas escolares. Tais medidas surgem como soluções técnicas e políticas para a resolução de problemas de ineficiência administrativa dos sistemas escolares ou da busca de adequação e racionalização dos recursos existentes, acompanhada da ideia de transparência (prestação de contas e demonstração de resultados) e de participação local. De maneira geral, têm acompanhado a tendência de retirar cada vez mais do Estado seu papel executor e transferir para a sociedade - esta, muitas vezes traduzida de forma simplificada como o mercado - a responsabilidade pela gestão executora de serviços, alterando a relação com o público atendido. (Oliveira, 2009, p. 47-48).

Maués (2008) explica que essas redefinições no papel do Estado em suas relações com a sociedade e o mercado se dão na esteira do processo de globalização, que impõe um movimento de reforma nos estados nacionais com o fito de solapar as bases do então dominante modelo de administração burocrático-estatal, trocando-o pelo modelo gerencialista do New Public Management ou pós-burocrático, no qual se prima pela descentralização das responsabilidades, pelo controle rigoroso dos resultados, pela eficiência dos processos, pela diluição das fronteiras entre o público e o privado, em suma, pelo que se convencionou chamar de Estado Neoliberal. A utilização da expressão pós-burocrática aparece em contraposição ao modelo burocrático fundado na legitimidade da razão e da racionalidade de valores e de lei. Weber (1963) identifica o Estado racional (burocrático) com o estado moderno ocidental, pautado em um direito racional e em uma burocracia profissional.

Chama-se a atenção, com base em Barroso (2006, p. 60), para o fato de que "não se pode reduzir a análise da regulação [...] a uma simples passagem entre a regulação pelo Estado e a regulação pelo mercado", ou regulação burocrática e regulação pósburocrática. Nessa lógica, Barroso destaca que não existe um "macroactor", mas que 
existem diferentes níveis que estão em interação e que seguem "racionalidades, lógicas, interesses e estratégias distintas".

Essas modificações estruturais na gestão do Estado capitalista obviamente tiveram rebatimentos sobre a área da educação, evidenciados pela descentralização das ações, pela avaliação dos resultados, pela centralização das decisões relativas ao processo pedagógico. Maroy (2006, p. 53) explicita o que ele chama de "duas variantes de um regime de regulação pós-burocrática" em relação à educação: a regulação pelo quasemercado, na qual o Estado tem um papel de suma importância que é de definir os objetivos do sistema de ensino e o currículo a ser adotado. 0 outro papel desse Estado pós-burocrático seria de "governar pelos resultados" 2.

0 controle dos resultados com a finalidade de manutenção do equilíbrio do sistema é a função primordial da avaliação (seja ela de sistemas escolares ou não), na perspectiva dos autores que trabalham com a teoria da regulação social. Tal função, contudo, só pode ser percebida se a avaliação é estudada num contexto mais amplo das mudanças sociais, neste sentido:

0 estudo da avaliação educacional lenquanto vector estruturante de uma política pública como a educaçãol não pode deixar de considerar as eventuais mudanças nas formas de regulação social lessencialmente ao nível do Estado, do mercado e também da comunidadel que se vão verificando, no âmbito de cada país, como resultado da interacção de factores internos e externos, e que actualizam as funções atribuídas a essa mesma avaliação. (Afonso, 2009, p. 17).

Em razão disso, seria adequado atualmente falar de um Estado-Regulador e Avaliador por conta das redefinições ocorridas nas últimas duas décadas nas suas funções em âmbito internacional, as quais apontam para a regulação e o controle dos mais diversos setores sociais.

Esta questão da avaliação é o que nos interessa neste trabalho, o qual busca identificar as relações existentes entre essa regulação na pós-graduação e o trabalho docente. A avaliação externa, de resultados, que ocorre ao final de uma etapa, é um dos mecanismos atuais que vem servindo para o Estado exercer seu papel de controle, exigindo que os sistemas educacionais façam o accountability ${ }^{3}$, tendo como parâmetros indicadores estabelecidos com base em níveis considerados performáticos.

2. Tradução livre do original: "Deux variantes d'un regime de régulation pós-bureaucratique"; "Gouvernance par les résultats".

3. Segundo Afonso (2009), apesar de comumente ser traduzido como "prestação de contas", o conceito de origem inglesa possui certa instabilidade semântica, pois ora se aproxima mais do sentido de "responsabilização" ou mesmo, quando se trata de políticas de avaliação de sistemas educacionais, sintetiza um tripé "avaliação, prestação de contas e responsabilização". 0 fato é que o "accountability" refere-se a um instrumento de gestão que, no campo educacional, é indispensável aos objetivos de redução de custos, regulação e controle dos sistemas educacionais na atual fase de gestão do Estado capitalista. 
Com esse tipo de "desenho avaliativo", a prestação de contas passa a desempenhar um papel fundamental nas ações que ocorrem nos sistemas educacionais (inclusive no sistema de pós-graduação), e que envolvem basicamente a gestão e o trabalho docente, os quais passam a ser considerados fundamentais para que os resultados sejam atingidos. A obrigação de resultados passa a ser o grande balizador das ações pedagógicas, e é uma das funções do Estado Avaliador. Yves Lenoir (2004) assinala que a "obrigação de resultados" é decorrente da cultura comercial e se inscreve na lógica neoliberal.

A importância da avaliação é tema recorrente entre os estudos de matrizes teóricas, políticas e ideológicas diferentes, mas as divergências aparecem por conta da compreensão do papel e das funções que esta deve desempenhar e qual a utilização será feita com os resultados apresentados. A avaliação institucional não é instrumento de medida de atividades ou indivíduos isolados, nem de trabalhos. A avaliação deve ter tanto um papel proativo, que antecipe as ações que as instituições devem adotar, bem como reativo, que busque através da identificação de problemas e obstáculos a correção de rota, a partir das finalidades da instituição, as quais devem servir de parâmetro para todas as atividades, inclusive para a avaliação.

\section{O V Plano Nacional de Pós-graduação e o Sistema 'Capes' de avaliação: expressão da nova regulação educativa na pós-graduação}

Para entendermos de que forma o sistema Capes de avaliação da pós-graduação no Brasil expressa os contornos da nova regulação educativa, é necessário reconstruirmos, ainda que ligeiramente, a história das mudanças dos cinco planos nacionais de pós-graduação a fim de estabelecermos as ligaç̃oes entre os diferentes conteúdos dos planos e os contextos histórico-sociais nos quais foram construídos.

Anteriormente à ditadura empresarial-militar (1964-1984), não existia no Brasil um sistema de pós-graduação efetivamente constituído. As primeiras experiências de estudos pós-graduados se reduziam a núcleos de estudos desenvolvidos por professores estrangeiros foragidos da segunda guerra mundial ou membros de comissões acadêmicas que tinham uma relação tutorial com um pequeno número de discípulos. Apenas em 1965 o então Conselho Federal de Educação aprovou o Parecer no 977 (Brasil, 2005), conhecido como Parecer Sucupira ${ }^{4}$, que passou a reconhecer as experiências de estudos pós-graduados e traçou o primeiro formato institucional da

4. O Parecer passou a ser conhecido pelo nome do Relator do Processo, professor Newton Sucupira. 
pós-graduação brasileira, diferenciando esse novo segmento do ensino superior em dois níveis: o mestrado e o doutorado. Posteriormente ao Parecer Sucupira, as políticas para a pós-graduação no Brasil entram em uma nova fase, a fase da elaboração dos planos nacionais de pós-graduação (PNPG).

Ao todo, tivemos cinco planos que se modificaram conforme as oscilações conjunturais e estruturais de nossa história. O I PNPG teve vigência de 1975-1980 e estabeleceu como prioridade a capacitação de docentes para instituições de educação superior e a integração das atividades de pós-graduação dentro do próprio sistema universitário.

No II PNPG (1982-1985), o objetivo central explicitado pelo plano era melhorar a qualidade do ensino superior e da pós-graduação. Já neste plano a avaliação como instrumento de regulação começa a ganhar destaque junto com o novo papel assumido pela Capes dentro do sistema federal de ensino, em especial após a extinção do Conselho Nacional de Pós-graduação.

No III PNPG (1986-1989), definiu-se como locus privilegiado de produção do conhecimento - enfatizando seu papel no desenvolvimento nacional - a universidade. Com base nessa compreensão, a pesquisa passou a ser entendida como indissociável da pós-graduação, e esta como indispensável aos progressos da ciência e da tecnologia do Brasil.

O IV PNPG (1998-2002), a despeito de sua história curiosa - pois a maioria dos sujeitos envolvidos na época (reitores, pró-reitores, coordenadores de programas de pós-graduação etc.) sequer lembra do documento enviado pelo MEC com esse título - sobretudo a partir de 2001 atuou como um documento complementar sobre avaliação e pós-graduação profissionalizante (Mancebo, 2008). Nele, surge a opção por uma pósgraduação que se desenvolvesse a partir de duas vertentes: a acadêmica, com o objetivo de formar pesquisadores, e a profissionalizante, com o objetivo de formar quadros técnicos não necessariamente voltados à pesquisa e à produção de conhecimento.

O V PNPG (2005-2010), ainda em vigência, enfatiza de maneira mais agressiva a diversificação do sistema iniciada com o IV PNPG e aprofunda a indução da demanda por meio da concessão de bolsas e fomentos às áreas do conhecimento e às regiões consideradas estratégicas para o governo (Mancebo, 2008).

As prioridades presentes no texto do V PNPG são bastante abrangentes: fortalecimento das bases científicas, tecnológicas e de inovação; capacitação do corpo docente para o ensino superior; qualificação dos professores da educação básica; especialização de profissionais para o mercado de trabalho e a formação de técnicos e pesquisadores para atuar nas empresas. Essas prioridades, que são traduzidas em metas e estratégias no documento, apontam para uma maior integração com o setor produtivo e para uma flexibilização do sistema de pós-graduação brasileiro para expandir esse 
nível de ensino ao mesmo tempo em que aumenta a inserção da pós-graduação como agente do desenvolvimento econômico e social conforme os objetivos do governo, segundo informa Mancebo (2008).

A opção pela flexibilização do sistema de pós-graduação, segundo a própria agência (Brasil/Capes, 2004), significa essencialmente: romper com a matriz sequencial que prevê o mestrado como condição obrigatória para o doutorado; incentivar a estruturação de programas multidisciplinares, o que supõe a construção de mecanismos de avaliação igualmente flexíveis; incentivar a conformação de consórcios, grupos e programas interinstitucionais, o que modificará o critério de financiamento que tenha a unidade acadêmica como base de cálculo; incluir critérios de avaliação qualitativa e uma maior flexibilidade na avaliação, que inclua, além dos indicadores básicos de desempenho, a capacidade do programa em dar respostas aos desafios do país; inserir os programas de pós-graduação no circuito internacional de produção e socialização de conhecimentos; formar profissionais de perfis diferenciados para atender à demanda dos setores acadêmicos e não-acadêmicos, isto é, do mercado.

Em entrevista concedida no ano de 2007, Jorge Guimarães, presidente da CAPES, deixa claro o que pensa sobre a relação entre a pesquisa e o setor privado, bem como sobre qual deve ser um dos eixos de financiamento dos estudos da pós-graduação brasileira, revelando uma concepção de educação e sociedade sintonizada com os pressupostos da nova regulação educativa. Nessa entrevista, ele externa suas ideias relativas ao afastamento das empresas em relação à pós-graduação, comparando o Brasil a outros países em que essa é uma prática comum (investir nesse nível). Há uma explicitação da necessidade de trabalhar junto à Confederação Nacional da Indústria no sentido de obter mais recursos, o que, segundo o presidente, possibilitaria um aumento do número de bolsas.

Sintetizando uma análise crítica do V PNPG, Mancebo (2008) expõe seus pressupostos teóricos e intencionalidades subjacentes aos discursos e práticas que operacionalizam o atual plano em vigor:

0 arcabouço teórico-metodológico que fundamenta o V PNPG sustenta-se, em boa parte, no pragmatismo, que busca submeter a universidade e, neste caso, a pós-graduação a concepções instrumentais e utilitaristas, vinculadas aos interesses imediatos seja do mundo dos negócios seja dos interesses da nação, tal como formulados por seus idealizadores, reservando à produção do conhecimento e à ciência uma função de eficácia prática. Assim, a atualização e a inserção da universidade e da pós-graduação na nova realidade postulada pelas políticas de Estado e mais especificamente pelo V PNPG implicam revisões de suas formas de organização, do relacionamento de seus atoreschave e a adoção de novos parâmetros, que tratam a produção do conhecimento de 
forma seletiva, priorizando aqueles grupos que têm algo imediato a oferecer às necessidades requeridas para o país, não raramente confundidas como uma mera adaptação às novas exigências do setor produtivo. (Mancebo, 2008, p. 183).

Tal concepção pragmática e utilitarista da pós-graduação parece expressar-se de forma direta no modelo de avaliação da Capes, que reflete a lógica da nova regulação educativa, conforme analisamos em parágrafos anteriores.

\section{O Sistema Capes de Avaliação e o Trabalho Docente}

O Sistema de Avaliação da Pós-Graduação, conhecido como Sistema Capes, foi implantando pela Agência em 1976. Desde então, é de sua incumbência definir os critérios que estabelecem o padrão de qualidade exigido para a autorização, reconhecimento e renovação de reconhecimento dos cursos de mestrado e doutorado do Brasil. o Sistema de Avaliação abrange dois processos conduzidos por comissões de consultores: a Avaliação dos Programas de Pós-graduação e a Avaliação das Propostas de Cursos Novos de Pós-graduação.

A Avaliação dos Programas de Pós-graduação compreende a realização do acompanhamento anual e da avaliação trienal do desempenho de todos os programas e cursos que integram o Sistema Nacional de Pós-graduação. Os resultados desse processo, expressos pela atribuição de uma nota na escala de 1 a 7, fundamentam a deliberação do CNE/MEC sobre quais cursos obterão a renovação de reconhecimento, a vigorar no triênio subsequente. A Avaliação das Propostas de Cursos Novos de Pós-graduação é parte do rito estabelecido para a admissão de novos programas e cursos ao Sistema Nacional de Pós-graduação.

Os dois processos - avaliação dos programas de pós-graduação e avaliação das propostas de novos programas e cursos - são alicerçados em um mesmo conjunto de princípios, diretrizes e normas, compondo, assim, um só Sistema de Avaliação, responsável pela regulação desse subnível de ensino.

Ao analisar a ficha de avaliação trienal 2008-2010, aprovada pelo Conselho Técnico Científico em sua $102^{\mathrm{a}}$ reunião, a qual serve de referência para o estabelecimento de critérios e aferição de conceitos dos programas já constituídos e autorização dos novos programas, observamos que o trabalho docente possui uma dimensão de centralidade no sistema de avaliação.

Para confirmar isso, basta observarmos os cinco quesitos que compõem a atual ficha de avaliação dos programas (1- Proposta do Programa; 2- Corpo Docente; 3Corpo Discente; 4- Produção Intelectual; 5- Inserção Sociall e os diversos itens que 
fazem parte dos critérios de avaliação de cada quesito. Mesmo em quesitos que aparentemente não dizem respeito ao docente, como o quesito 3 (Corpo Discente), os cinco itens que constituem esse quesito avaliam o corpo discente diretamente à luz da produção do trabalho docente. Vejamos os cinco itens que compõe o quesito 3: 3.1 Quantidade de teses e dissertações defendidas no período de avaliação, em relação ao corpo docente permanente e à dimensão do corpo discente; 3.2 Distribuição das orientações das teses e dissertações defendidas no período de avaliação em relação aos docentes do programa; 3.3 Qualidade das Teses e Dissertações e da produção de discentes autores da pós-graduação e da graduação (no caso de IES com curso de graduação na áreal na produção científica do programa, aferida por publicações e outros indicadores pertinentes à área; 3.4 Eficiência do Programa na formação de mestres e doutores bolsistas; 3.5 Tempo de formação de mestres e doutores e percentual de bolsistas titulados.

0 quesito 4 (Produção Intelectual), do mesmo modo, é avaliado diretamente pela quantidade e qualidade da produção científica, técnica e artística dos docentes que fazem parte do programa.

A ficha de avaliação 2008-2010 ainda reafirma, para efeito de atribuição de conceito, os pesos 0 (zero) para o quesito 1; Peso de $30 \%$ para os quesitos 2 e 5 somados; e peso de $70 \%$ para os quesitos 3 e 4 somados. Ou seja, os únicos quesitos que não se centram mais diretamente sobre a avaliação do trabalho do professor, os quesitos 1 (Proposta do Programa) e 5 (Inserção Social), são os que possuem menor peso para efeito de avaliação, e são os que exatamente dizem respeito ao papel social da pós-graduação, à concepção de formação e às responsabilidades científicas, políticas e sociais da pósgraduação brasileira.

O Sistema Capes de avaliação da pós-graduação, portanto, centra a avaliação dos programas no trabalho docente. As notas de cada programa refletem o grau de adequação do trabalho dos professores do programa às exigências de perfil e produção científica emanadas da Capes. Como o modelo é produtivista, não é à toa que fenômenos como a intensificação, autointensificação do trabalho e a grande recorrência de doenças ocupacionais têm sido fonte de sérias preocupações das pesquisas na área, como se pode notar inclusive nas investigações recentes da ANPEd. As mudanças que se verificam no trabalho docente na pós-graduação, desse modo, são tributárias, em grande medida, dessa nova regulação educacional que atribui à avaliação um poder de constrangimento e coerção nunca antes visto. Isso no que diz respeito à avaliação trienal, uma das vertentes da avaliação dos programas de pós-graduação.

No que toca ao acompanhamento anual, a Capes realiza uma coleta de dados junto aos programas de pós-graduação e condensa as informações no que chama de caderno 
de indicadores", que são os relatórios utilizados no processo de avaliação. Atualmente, os cadernos são compostos por 11 documentos, trazendo dados qualitativos sobre: 1- Produção Técnica; 2- Disciplina; 3- Proposta do Programa; 4- Docente Produção; 5- Teses e Dissertações; 6- Produção Artística; 7- Linhas de Pesquisa; 8- Docente Atuação; 9- Produção Bibliográfica; 10- Corpo Docente, Vínculo e Formação; 11 - Projetos de Pesquisa.

Mesmo no acompanhamento anual, a centralidade da avaliação no trabalho docente salta à vista, como se pode ver pelos próprios indicadores. Aspectos como infraestrutura dos programas, apoio técnico e financeiro dos governos, política de recursos humanos, integração do programa com a graduação e a extensão, relevância científica e social das linhas de pesquisa e produções, entre outros aspectos relacionados à totalidade das atividades da pós-graduação, são ou relegados a segundo plano ou sequer considerados critérios de avaliação. Responsabiliza-se quase que totalmente o docente pela qualidade dos programas.

Além disso, o grau de exigência feito pela Capes para que os programas avancem em sua qualidade e em sua avaliação não é acompanhado de suporte técnico e financeiro por parte do poder público para que os programas criem condições de cumprir as exigências postas para melhorar a qualidade do programa e, consequentemente, 0 próprio nível de apoio governamental. É um tipo de política que impede o que exige, visto que o caráter e o objetivo da avaliação não são a emancipação e a formação processual, mas a regulação e o controle.

As repercussões desse modelo de avaliação, entretanto, vão além do trabalho docente. Induzem a modificações sobre a própria identidade e cultura acadêmica. Tendências que vêm se aprofundando no atual processo de reconfiguração da universidade brasileira lem sua organização jurídico-institucional, em sua identidade, em suas relações com a sociedade) - tais como a transição de uma autonomia relativa para uma crescente heteronomia na produção de conhecimentos, por meio de ingerências do setor produtivo sobre a agenda e financiamento de pesquisas, tudo isso combinado com profundas mudanças na cultura acadêmica e no trabalho docente - introduzem no ambiente universitário, em especial na pós-graduação, um ethos empresarial estranho aos princípios do modelo de universidade humboldtiano, o qual afirma a autonomia universitária como elemento central para definição desta instituição.

Para o trabalho dos professores, o produtivismo acadêmico imposto pela nova regulação educativa expresso, entre outras políticas, na avaliação da Capes, trouxe cargas elevadas de sobretrabalho, doenças ocupacionais e mudanças culturais e comportamentais (individualismo, competitividade) que necessitam de aprofundamento teórico e prático por parte das pesquisas em educação. 
Leher e Lopes (2008) expõem a devida dimensão do que o modelo Capes de avaliação representa para o trabalho docente na atualidade:

Ao mesmo tempo, a avaliação da CAPES que outrora desempenhara um papel relevante na organização do sistema de pós-graduação brasileiro incorporou a mesma lógica produtivista, pragmática e utilitarista presente na GED e nos mecanismos de financiamento do Ministério de Ciência e Tecnologia, situação que alcança o paroxismo no Plano Nacional de Pós-graduação 2005-2010. Em lugar de avaliar o programa, suas dificuldades, potencialidades e relevância para a instituição e para a região, o resultado da avaliação depende de uma planilha de indicadores cujo foco incide diretamente sobre cada professor credenciado na pós-graduação: inicialmente, exigindo um padrão produtivista, depois, restringindo o campo possível desse produtivismo, impondo que as publicações sejam limitadas a um conjunto de periódicos qualificados e que a produção do conhecimento gere produtos úteis, utilidade essa que os Conselhos do Ministério de Ciência e Tecnologia, também composto por representantes das empresas, aferirão conforme a eficácia da pesquisa vis-a-vis ao mercado. (Leher; Lopes, 2008, p. 84-85).

\section{Trabalho Docente na Pós-Graduação: Metamorfoses e Tendências}

0 trabalho docente passa por significativas transformações, operadas por fatores como as políticas públicas para a educação e as mudanças estruturais na sociedade capitalista. As mudanças que se visualizam no trabalho docente, e que se dão também na pós-graduação, alvo de nosso estudo, são parte de um processo mais geral denominado de reestruturação do trabalho docente.

As profundas transformações pelas quais passa a atividade docente refletem o modo como ela se insere nas injunções estruturais e conjunturais do capitalismo. As mudanças no mundo do trabalho, desde a crise do fordismo até os atuais modelos de acumulação flexível, bem como a revolução tecnológica do último quartel do século XX, impactaram de modo indelével, e não raro negativamente, a natureza do trabalho docente. A inclusão das novas tecnologias da informação não trouxe somente avanços no que se refere ao maior e mais ágil acesso à informação, mas também tem servido de instrumento de intensificação do trabalho por parte dos gestores e empresários da educação, na medida em que o professor passa a levar trabalho para fazer em casa ou mesmo porque o uso do computador e da internet permite que as tarefas de preparação e organização do trabalho docente sejam agilizadas, permitindo assim maior concentração de trabalho numa mesma unidade de tempo.

Nos países periféricos como o Brasil, a reforma do Estado e as muitas políticas educacionais e ajustes estruturais impostas pelos últimos governos (face superestrutural 
da reestruturação produtival ditaram, sob a égide dos organismos internacionais do capital, os objetivos e o formato das mudanças nas universidades brasileiras na última década para que se ajustem ao processo de reestruturação do trabalho docente. Políticas como a GED (Gratificação de Estímulo à Docência), a Lei de Inovação Tecnológica, e mais contemporaneamente o REUNI (Decreto 6096/07), o rebaixamento salarial, as subcontratações, a falta de investimentos, entre outras políticas, são os exemplos concretos das relações entre as políticas públicas educacionais e a reestruturação do trabalho docente.

Contudo, interessa-nos aqui, mais especificamente, assinalar o que as pesquisas mais recentes sobre trabalho docente vêm apontando sobre as repercussões do modelo de avaliação da Capes sobre o trabalho dos professores na pós-graduação.

Bianchetti e Machado (2007), Leher e Lopes (2008), Silva e Silva Jr (2008), Maués $(2005,2008)$, ao estudarem as relações entre o trabalho docente e as políticas para a pós-graduação no Brasil, em particular as políticas de avaliação, vêm constatando fenômenos como a intensificação e a precarização do trabalho docente e a penetração crescente de um ethos empresarial que está modificando a cultura acadêmica nas universidades brasileiras e trazendo mudanças na subjetividade dos professores, os quais estão se tornando mais conformistas e competitivos. Isso tudo em um contexto de aprofundamento de um modelo de universidade menos autônomo e mais heterônomo.

São vários os fatores que impulsionam as modificações em curso no trabalho docente. Em relação ao fenômeno da intensificação, Dal Rosso (2008) aponta cinco instrumentos através dos quais se verifica a intensificação do trabalho (e do trabalho docente) na realidade: 1- alongamento da jornada de trabalho; 2 - aumento do ritmo de trabalho; 3- acúmulo de atividades; 4- polivalência na execução das tarefas; 5- organização da gestão do trabalho por resultados. Esses instrumentos da intensificação do trabalho docente na pós-graduação são fruto não só do "modelo Capes" de avaliação, mas da adoção de um modelo de gestão da pós-graduação cada vez mais próximo dos princípios e práticas empresariais incorporados a partir da implementação das políticas educacionais governamentais.

A propósito ainda dos processos de precarização e intensificação do trabalho docente nas universidades federais, Leher e Lopes (2008) demonstram como a expansão das matrículas tanto na graduação quanto na pós-graduação não é acompanhada de evolução correspondente no número de funções docentes, isso sem contar as perdas de direitos previdenciários, a defasagem salarial e a falta de investimentos em infraestrutura nas IES, que são do conhecimento de todos.

No período de 1996 a 2006, o número de matrículas na graduação cresceu 52\%, apresentando fôlego impressionante na pós-graduação, onde dados apontam para um 
crescimento de $71 \%$ para o mestrado, e 179\% para o doutorado. Estatísticas que registram a evolução do número de funções docentes, contudo, apresentam um crescimento bem mais modesto para o mesmo período: 23\% para a graduação, e $68 \%$ para a pósgraduação, o que significa que os docentes credenciados na pós tiveram uma intensificação extraordinária de sua jornada de trabalho, visto que não há contrato para docentes da pós-graduação. (Leher; Lopes, 2008, p. 89).

Sguissardi e Silva Jr. (2009), ao observarem essas modificações no trabalho docente, chegam a constatar a existência de uma dupla carreira docente nas IFES: a prescrita e a efetiva. A prescrita seria a que preconiza o Regime Jurídico Único e a Constituição Federal de 1988, que asseguram a isonomia e a autonomia universitária; e a efetiva seria a que tem como base o produtivismo acadêmico e a competição por recursos públicos ou privados, induzida pela Capes, pelo CNPq e pelo mercado, tornando-se a pós-graduação o espaço mediador da concretização da carreira efetiva, enquanto a carreira prescrita não passa de um instrumento para gestão de pessoal.

O modelo Capes de avaliação da pós-graduação tem sido o alvo principal das pesquisas que buscam estudar o porquê de tantas modificações no trabalho docente no sistema de pós-graduação no Brasil.

Bianchetti e Machado (2007) defendem que houve uma série de mudanças no campo de trabalho dos pesquisadores nas últimas décadas, fruto das transformações em grande escala advindas com a globalização. Tais mudanças no campo de trabalho consolidaram uma tendência a tornar os professores da pós-graduação o que eles denominam de “reféns da produtividade", tanto no âmbito de seu trabalho, isto é, da produção de conhecimento, quanto na saúde desses trabalhadores e trabalhadoras.

Maués (2008) estabelece um importante link entre esse modelo de avaliação, considerando-o como uma manifestação concreta das novas regulações pós-burocráticas para a educação, e o trabalho dos professores na pós-graduação no Brasil, explicitando que os docentes da pós-graduação estão sendo alvo de uma regulação pós-burocrática, ou seja, aquela que tem a centralidade na obrigação dos resultados, devendo estes estarem de acordo com o mercado.

No âmbito do seu processo de trabalho, os professores tiveram como consequência das exigências produtivistas da Capes (expressas nos quesitos da Ficha de Avaliação), um aumento brutal em sua carga de trabalho (em termos absolutos e relativos), entendido como intensificação de suas atividades, e uma desqualificação de sua produção, visto que as obrigações com as exigências da agência levam a uma deterioração das condições de produção, em particular no que se refere ao tempo de criação e à autonomia para produzir.

No que toca à saúde dos docentes da pós-graduação, nunca se diagnosticou tanto estresse, depressão, insônia e síndrome de bournout lo que inclusive tem se refletido 
nos alunos da pós-graduação). Mesmo com todas as inovações tecnológicas difundidas nas últimas duas décadas, há uma tendência a que os docentes da pós-graduação sejam cada vez mais acometidos por síndromes resultantes de mais-trabalho.

Por outro lado, pensava-se uma década atrás que os artefatos tecnológicos seriam responsáveis por um tempo maior de ócio ou lazer e propiciariam a redução da jornada de trabalho. Porém, tal previsão mostrou-se equivocada. 0 ócio esperado tornou-se desemprego e o trabalho informal, precarizado gerou uma jornada que não precisa ser controlada por relógios-ponto ou chefias, nem precisa de local de trabalho presencial. A vida privada foi invadida; diluiram-se os limites entre o local de trabalho e o lar. Com o suporte das chamadas novas tecnologias o trabalho acontece em qualquer tempo e lugar, não raro invadindo o tempo do necessário sono, full time, sem direito a hora extra! (Bianchetti; Machado, 2007, p. 04).

\section{Considerações Finais}

Pode-se concluir, tal como atestam as pesquisas nas quais nos baseamos acerca das relações entre regulação educativa com ênfase para avaliação e trabalho docente na pós-graduação nos últimos anos, que a natureza do trabalho docente a ser desenvolvido em uma instituição universitária é incompatível com as imposições que o capital busca processar às custas do estrangulamento da autonomia universitária e da alienação do trabalho.

É importante, contudo, situar que as tendências que se operam sobre o trabalho docente na pós-graduação brasileira não são um caminho de mão única. Há resistências, contradições e mediações, apesar do aparente pessimismo e dos diagnósticos nada entusiasmados das pesquisas. Em recente pesquisa concluída por Sguissardi e Silva Jr. (2009), a propósito das modificações que vêm se processando sobre o trabalho docente nas universidades federais da região sudeste a partir do processo de reforma do estado e da educação superior, os autores relatam as diferentes maneiras pelas quais os professores encontram formas para resistir, em que pese o enfraquecimento sindical da categoria e os ataques que a educação e o mundo do trabalho vêm sofrendo. Ainda que de maneira isolada e desorganizada, há questionamentos e resistência.

Investigar o trabalho docente em suas manifestações concretas, seja na rede privada ou na rede pública, na educação básica ou na educação superior, a partir das novas regulações educativas é fundamental para o entendimento e para a proposição de alternativas aos problemas educacionais sob todos os seus aspectos, pois não há escola nem ensino sem professor e professora. 
Tendo em vista a importância desse objeto de estudo, consideramos como extremamente necessários os estudos sobre a temática e apontamos como tarefa urgente o prosseguimento e a difusão de mais pesquisas e produções científicas acerca das condições de realização do trabalho docente na atualidade e sobre os impactos que as políticas públicas (em especial as de avaliação) e as transformações no mundo do trabalho trazem para estes sujeitos determinantes para o processo educativo que são os docentes.

\section{Referências}

AFONSO, Almerindo Janela. Avaliação educacional: regulação e emancipação. 4. ed. São Paulo: Cortez, 2009.

AGLIETTA, Michel. Régulation et crises du capitalisme. Paris: Editions Odile Jacob, 1997.

BARROSO, João (Org.). A regulação das políticas públicas de educação: espaços, dinâmicas e actores. Lisboa: Educa, 2006.

BIANCHETTI, Lucídio; MACHADO, Ana Maria Netto. "Reféns da Produtividade" Sobre produção do conhecimento, saúde dos pesquisadores e intensificação do trabalho na pós-graduação. In: 30a reunião anual da ANPEd. Caxambú, 2007. Disponível em: <http://www.anped.org.br/reunioes/30ra/ trabalhos/GT09-3503-Int.pdf>. Acesso em: 18 dez. 2010.

BRASIL. CFE. Parecer nº 977 de 03 de dezembro de 1965. Revista Brasileira de Educação, Brasília, n. 30, p. 5-12, 2005.

BRASIL. CAPES. V Plano Nacional de Pós-graduação - 2005-2010. Brasília: CAPES, 2004. Disponível em: <http://www.capes.gov.br>. Acesso em: 20 dez. 2009.

GUIMARÃES, Jorge Almeida. Cursos de Pós do Brasil têm prestígio no exterior. São Paulo, Folha dirigida. 26/06/2007. Caderno especial professor.

LEHER, Roberto; LOPES, Alessandra. Trabalho docente, carreira, autonomia universitária e mercantilização da educação. In: MANCEBO, Deise; SILVA JR, João dos Reis.; OLIVEIRA, João (Org.). Reformas e Políticas: educação superior e pós-graduação no Brasil. Campinas: Alínea, 2008.

LENOIR, Yves. Pour une éthique de l'évaluation des résultats en éducation: quelles compatibilités entre les attentes néolibérales et les visées éducatives? In : LESSARD, Claude; MEIRIEU, Philippe. L'Obligation de Résultats en Éducation. Québec: Presses de l'Université Laval, 2004.

MANCEBO, Deise; SILVA JR, João dos Reis.; OLIVEIRA, João (Org.). Reformas e Políticas: educação superior e pós-graduação no Brasil. Campinas: Alínea, 2008.

MAROY, Christian. École, regulation et marché: une comparaison de six espaces scolaires locaux en Europe. Paris: Puf, 2006.

MAUÉS, Olgaíses Cabral. A política de educação superior para a formação e o trabalho docente: a nova regulação educacional. In: 31a reunião anual da ANPEd. Caxambú, 2008. Disponível em: <http://www.anped.org.br/reunioes/31ra/trabalhos/GT11-2988-Int.pdf>. Acesso em: 20 jan. 2010. 
OLIVEIRA, Dalila Andrade. Política Educacional e Regulação no Contexto latino-americano: Argentina, Brasil e Chile. Linhas Críticas, Brasília, v. 15, n. 28, p. 45-62, 2009.

SGUISSARDI, Valdemar; SILVA JR., João dos Reis. Trabalho intensificado nas federais: pós-graduação e produtivismo acadêmico. São Paulo: Xamã, 2009.

SILVA JÚNIOR, João dos Reis; SILVA, Eduardo Pinto. Carreira docente diante da atual configuração da pós-graduação: pragmatismo, intensificação e precarização do trabalho do professor. In: MANCEBO, Deise; SILVA JÚNIOR, João dos Reis.; OLIVEIRA, João. Ferreira de (Org.). Reformas e políticas: educação superior e pós-graduação no Brasil. São Paulo: Xamã, p.189-222, 2008.

WEBER, Max. Ensaios de sociologia. Rio de Janeiro: Zahar, 1963.

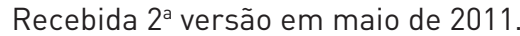

Aprovada $2^{\text {a }}$ versao em junho de 2011.

Olgaíses Cabral Maués, doutora em Sciences de L'éducation - Université des Sciences et Technologies de Lille III, Lille, França e estudos de pós-doutorado na Université Laval, Quebec, Canadá. É bolsista de produtividade em pesquisa do CNPq e professora associada da Universidade Federal do Pará. Atua na Graduação e na Pós-Graduação em Educação, coordenando a Linha de Pesquisa Políticas Públicas em Educação; coordena o Grupo de Pesquisa sobre Políticas Educacionais, Formação e Trabalho Docente. Publicação recente: A Política da OCDE para a educação e a formação docente. A nova regulação? (Revista Educação, PUC-RS, v. 34, 2011). E-mail: olgaisesवuol.com.br

William Pessoa da Mota Junior, mestre em educação pela Universidade Federal do Pará na linha de Políticas Públicas Educacionais e membro do Grupo de Estudos e Pesquisa sobre Políticas Educacionais e Trabalho Docente (Gestrado) da UFPA. E-mail: will_motadyahoo.com.br 